Pak. j. sci. ind. res. Ser. B: biol. sci. 201457 (2) 92-96

\title{
Evaluation of Growth Performance of Broiler Chicks Fed with Raw and Processed Leucaena leucociphala Seed
}

\author{
Joseph Bamidele Minari ${ }^{a *}$, Agboola Adewale Odutuga ${ }^{b}$, Fisayo Abraham Bamisaye ${ }^{c}$, \\ Joshua Olugbenga Dairo ${ }^{b}$ and Leye Jonathan Babatola ${ }^{b}$ \\ ${ }^{a}$ Department of Cell Biology and Genetics, University of Lagos, Akoka, Lagos 100001, Nigeria \\ ${ }^{b}$ Department of Biochemistry, Joseph Ayo Babalola University, Ikeji-Arakeji, P.M.B 5006, Ilesa, \\ Osun State, Nigeria \\ ${ }^{\mathrm{c}}$ Department of Biochemistry, Biosciences and Biotechnology, College of Pure and Applied Sciences, \\ Kwara State University, Malete, Nigeria
}

(received May 15, 2013; revised January 7, 2014; accepted January 20, 2014)

\begin{abstract}
Fourty-eight broiler chicks (day-old) were used in a 4 weeks feeding experiment to assess the growth response and the performance of broiler chicks fed raw Leucaena leucociphala seed meal (RLSM), roasted L. leucociphala seed meal (RoLSM) and steamed L. leucociphala seed meal (SLSM). The L. leucociphala seed, which serve as a source of protein were subjected to two treatments (roasting and steaming). Soybean based diet served as the control. There were four (4) experimental groups, each made up of four birds in three replicates allocated to the experimental diets. The results showed that the average final live weight, average weekly weight gain and average feed intake of birds fed with RoLSM performed better than birds fed with RLSM and SLSM. It was observed that the percentage organ to body weight of birds fed with the processed LSM were significantly $(\mathrm{P}<0.05)$, higher as compared to the RLSM. A significant $(\mathrm{P}<0.05)$ increase in the activity of aspartate transferase in the organs (heart, kidney and liver) of broilers fed with RoLSM was observed as compared to those fed with RLSM. The results showed a significant $(\mathrm{P}<0.05)$, reduction in the activity of alanine transferase of organs of broilers chicks fed with processed L. leucociphala compared to the control. It is therefore, concluded that the processing techniques applied were able to improve the nutritional quality of $L$. leucociphala seed meal but relatively lower to the soybean based meal.
\end{abstract}

Keywords: growth performance, Leucaena leucociphala, transferase, broiler chicks

\section{Introduction}

Protein sources for body requirement are mainly of animal sources such as poultry. Worldwide poultry production therefore, has been increased significantly, over the past decades to accommodate the rising demand. One of the utmost drawbacks, however, to the growth of poultry industry is the high cost of the standard commercial feed, which affects the prices of poultry products (MacDonald, 2008). Feed is the most important input for poultry production in terms of its cost (May et al., 1998), accounting for around 75 percent of the total expenses (Nakaue and Arscott, 1991). A lowpriced, high-quality feed is critical if poultry production is to remain competitive and continue to grow to meet the demand for animal protein. A necessity therefore, arises for the quest into the possible ways of obtaining maximum production in poultry with minimum

*Author for correspondence; E-mail: baminjoe@yahoo.co.uk expenditure, so that the products can be sold at a relatively low price with similar or even better nutritional quality than conventional ones. A very good class of plants that can be exploited for this purpose is the legumes (Agbede, 2000). The role of grain legumes in the diets of animal and man in developing countries is well documented (Agbede, 2000). Legumes have also been reported as very important source of protein, lipid and other nutrients like minerals and vitamins required for the proper growth of chicks (Baraniak and Swieca, 2008).

However, the quality of leguminous plants is influenced by the antinutritional factors present in them, which make them unsuitable for consumption in their native form. Utilisation of seed legumes as a source of protein for poultry is limited by the uncertainty of their nutritional quality. This may be due to variation of protein quality and amount of antinutritional factors and a wide range 
of methods for thermal inactivation of antinutritional factors of legumes has been studied (Wiryawan, 1997). (Wiryawan, 1997). It is also known that processing techniques like roasting, steaming, autoclaving and boiling can improve nutritional quality and bioavailabilty of nutrients present in legumes. Leucaena leucociphala seed has been known to be a protein rich forage plant. The seeds are readily available and can be obtained with little or no cost. This is an indication that it may reduce feed cost and make poultry production more lucrative if found appropriate for poultry.

This study was therefore, carried out to evaluate the growth performance of broiler chicks fed with raw and processed L. leucociphala based diet.

\section{Materials and Methods}

Chemicals and reagents. All chemicals and reagents used were of analytical grade.

Leucaena leucociphala seed. L. leucociphala seeds were purchased at the Leventis Foundation (Nigeria) Limited, Ilesa, Osun State, Nigeria.

Feed ingredients. Feed ingredients such as maize bran, wheat offal, bone meal, oyster shell, soybean, vitamin-mineral mixture and all vaccines used for the birds were purchased at Iyanu-oluwa feeds mill, Ilesa, Nigeria.

Experimental birds. A total of 48 day-old broiler chicks weighing an average of $38 \pm 0.43 \mathrm{~g}$ were purchased from Ben-Adex Nigeria Limited, Ibadan, Oyo State, Nigeria.

Preparation of soybean seed. After cleaning, the beans were dried thoroughly so the hull can be easily removed. The soybean was then rolled into full-fat flakes and the oil was solvent extracted. The soy flakes were then milled using a local grinder to give the smooth seed samples.

Preparation of the raw $L$. leucociphala seed. L. leucociphala seeds were firstly sieved to remove unwanted matter such as leaves, sands etc., and then milled using a local grinder to give the smooth seed samples.

Preparation of roasted $L$. leucociphala seed. L. leucociphala seeds were roasted in a dry pan using an electrical hot plate. The seed meal was continually stirred until a characteristic brownish coloured seeds were obtained. The seeds were then milled and sieved to remove the seed coat.
Preparation of steamed L. leucociphala seed. The L. leucociphala were washed, put in cooking pot and boiled for 40 mins, on a gas cooker at $\mathrm{STP}\left(100{ }^{\circ} \mathrm{C}\right.$, $760 \mathrm{~mm} / \mathrm{Hg}$ ).

Management of experimental birds. Fourty-eight dayold broiler chicks were used for the experiment. The environment, where the birds were kept was cleaned and disinfected three days before the arrival of the chicks. The feeders and drinkers were also washed and disinfected. The electrical appliance that supplies heat was properly checked and was switched on few hours before the arrival of the birds. The cage was covered with white polythene to provide warmth. On arrival of the birds, they were distributed into four dietary treatment groups. Each treatment had three replicate groups with four birds per replicate. The birds were supplied with feed and water ad-libitum. They were acclimatised to their new environment for one week. The individual weight of the birds was taken prior to the commencement of the experiment and this was done thereafter, on a weekly basis. The feeding troughs and drinkers were washed daily and replaced with new feeds and drinks, respectively. The litters were also emptied on a daily basis. Vaccinations and medications were administered as, and when due. The experiment lasted for four weeks.

The growth parameters. The birds were placed on the experimental diets for a period of four weeks during which feed intake, body weight gain, feed conversion ratio and percentage mortality were determined.

Relative organ measurement. The liver, kidney, heart, lungs and gizzard were dissected out from the experimental birds. The organs were blotted clean with tissue paper, weighed and the weight expressed in $\%$ organ to body weight.

Enzyme analysis. Three hours to the close of the feeding trial, the birds were starved. Thereafter, the birds were weighed and sacrificed by severing the jugular vein with a sharp blade. A section of the heart, kidney and liver of the birds were homogenised in ice-cold $0.25 \mathrm{M}$ sucrose solution $(1: 5 \mathrm{w} / \mathrm{v})$ and centrifuged for 4000 rpm for 10 mins. Aspartate transferase and alanine transferase were determined by the methods of Reitman and Frankel (1957).

Statistical analysis. Data were subjected to the analysis of variance (SAS, 1985) and the significant difference between the treatments and control were determined using Duncan's multiple range test (Duncan, 1955). 


\section{Results and Discussion}

Average body weight gain of broilers fed with experimented diets was observed over a period of 28 days. The average final weight gain of broiler chicks fed with the control diet (Fig. 1) was significantly higher $(\mathrm{P}<0.05)$ than those fed with raw Leucaena leucociphala seed meal (RLSM), roasted L. leucociphala seed meal (RoLSM) and steamed L. leucociphala seed meal (SLSM). This observation agrees with that of Sethi and Kulkarni (1995), who reported a reduction in weight with increased intake of $L$. leucociphala in broiler diets. This could be as a result of the presence of antinutrients, which the processing technique were unable to sufficiently reduce hence, causing retarded growth (Martinez et al., 1995).

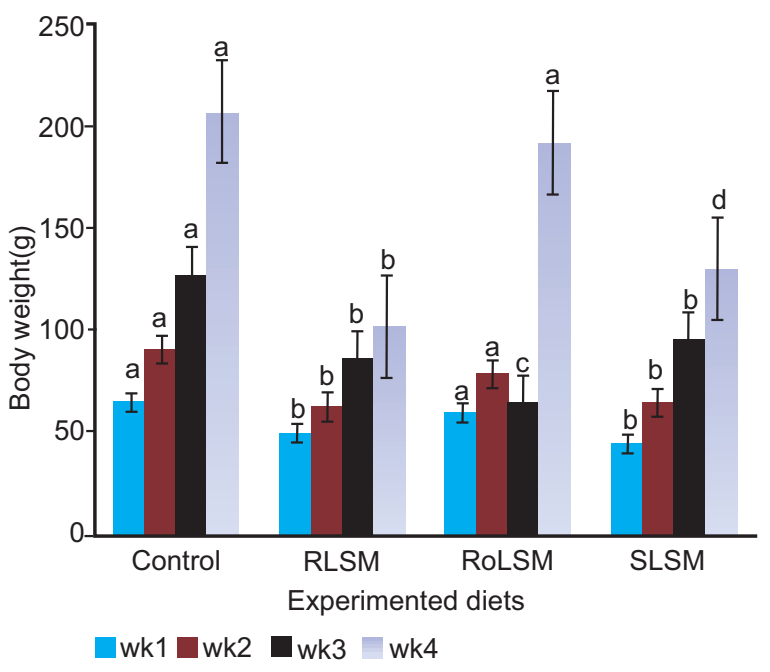

Fig. 1. Average body weight gain of day-old broilers fed experimented diets over a period of 28 days.

Values are means of 3 replicates per treatment $( \pm \mathrm{SD})$. Means with different superscripts in the same row are significantly different $(\mathrm{P}<0.05)$.

Control $=$ Soybeans meal; RLSM = Raw Leucaena seed meal; RoLSM = Roasted Leucaena seed meal; $\mathrm{SLSM}=$ Steamed Leucaena seed meal.

Antinutritional factors have been reported to lower digestibility of legume proteins (Elegbede, 1998). At the end of the $4^{\text {th }}$ week, the average weight gain of birds fed with RoLSM and SLSM were observed to be higher than that fed with RLSM. This might be due to the reduction in the antinutritional factor present in the processed experimental diet. Processing techniques such as roasting and steaming has earlier been reported to significantly, reduce the presence of antinutrients in L. leucociphala seed (Minari et al., 2012). The percentage organ to body weight ratio of the birds is shown in Fig. 2. It was observed that the percentage organ to body weight of birds fed with the processed LSM are significantly $(\mathrm{P}<0.05)$, higher as compared to the raw LSM. From this study, it is evident that the processed diet had significant influence on the organs weighed. This suggest relative similar organ enhancement by the control as well as the processed diet.

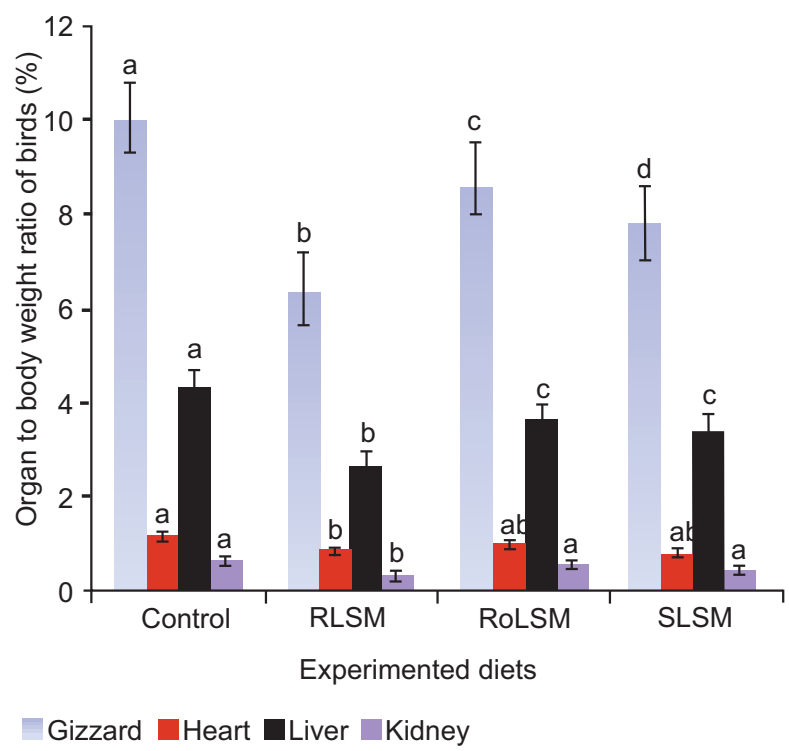

Fig. 2. The percentage organ to body weight ratio of day-old broilers fed experimented diets over a period of 28 days.

Values are means of 3 replicates per treatment $( \pm S D)$. Means with different superscripts in the same row were significantly different $(\mathrm{P}<0.05)$.

Control $=$ Soybeans meal; RLSM = Raw Leucaena seed meal; RoLSM = Roasted Leucaena seed meal; SLSM = Steamed Leucaena seed meal.

Figures 3 and 4 show the specific activity of some amino tranferases in various organs of broilers fed with various experimental diets. The measurement of the activities of various enzymes in tissues plays a significant role in disease investigation, diagnosis and tissue damage (Malomo, 2000). Aminotranferases are the most commonly used indicator of cellular necrosis and low levels in the organ may indicate malfunctioning (Burke, 2002).

In this study, although the specific activity of aspartate transferase (AST) in the liver, kidney and heart of the 


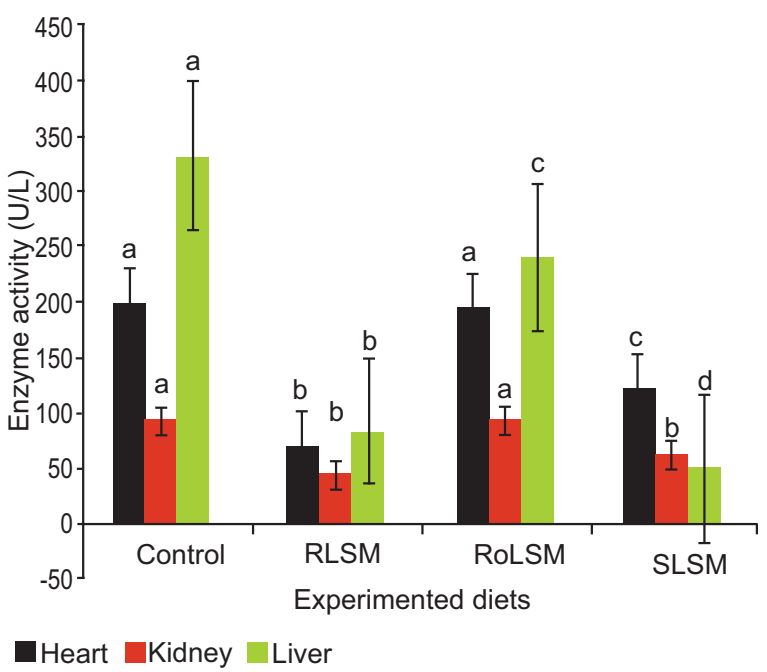

Fig. 3. The enzyme activity of aspartate transferase in some organs of day-old broilers fed experimented diets over a period of 28 days.

Values are means of 3 replicates per treatment $( \pm \mathrm{SD})$. Means with different superscripts in the same row were significantly different $(\mathrm{P}<0.05)$.

Control $=$ Soybeans meal; RLSM = Raw Leucaena seed meal; RoLSM = Roasted Leucaena seed meal; SLSM = Steamed Leucaena seed meal.

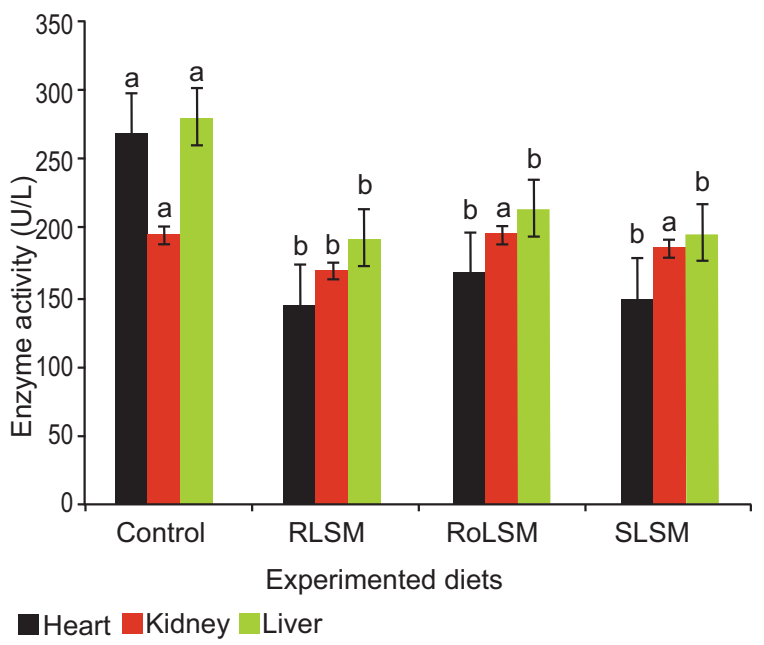

Fig. 4. The enzyme activity of alanine transferase in some organs of day-old broilers fed experimented diets over a period of 28 days.

Values are means of 3 replicates per treatment $( \pm \mathrm{SD})$. Means with different superscripts in the same row were significantly different $(\mathrm{P}<0.05)$.

Control = Soybeans meal; RLSM = Raw Leucaena seed meal; RoLSM = Roasted Leucaena seed meal; SLSM $=$ Steamed Leucaena seed meal. experimental birds fed with RoLSM was observed to be significantly lower $(\mathrm{P}<0.05)$ than the control diet, it showed a significant increase $(\mathrm{P}<0.05)$ as compared with that fed with SLSM and RLSM (Fig. 3). The elevation of the specific activities of this enzyme in the organs of the broiler chicks fed with RoLSM may be attributed to increase in functional activity of the organs. This tends to further confirm that roasting had actually, to some extent inactivated some of the antinutritional factors as reported earlier by Minari et al. (2012) A significant reduction $(\mathrm{P}<0.05)$ was observed in the specific activities of alanine transferase (ALT) in various organs of the broilers chick fed with raw and processed L. leucociphala seed meal compared with the control (Fig. 4). This may be due to leakage (cytolysis) in different organs of the broiler chicks fed with raw and processed L. leucociphala seed meal. These observations suggest that processing techniques applied in this study could not totally inactivate the antinutrients in the seed. Similar report had earlier been made by Oloyede et al. (2007) on the activities of these enzymes in different organs of birds fed with legumes such as bambara groundnut.

\section{Conclusion}

The present study evaluates growth performance and some enzymes found in the organ of broilers chicks. From the result obtained, it can be inferred that although broiler-chicks fed with roasted L. leucociphala seed performed better than broiler-chicks fed with raw and steamed L. leucociphala seed, it still demonstrates lower nutritional quality when compared with soybean based diet. It is therefore, concluded that some antinutrients were present in the L. leucociphala seed which could not be completely inactivated by processing techniques. Further research is therefore, suggested to carry out for other processing techniques that may reduce or eliminate the levels of antinutrients in L. leucociphala seed.

\section{References}

Agbede, J.O. 2000. Biochemical Composition and Nutritive Quality of the Seeds and Leaf Protein Concentrates from Under-utilized Tree and Herbaceous Legumes. Ph.D Thesis, 293 pp., Federal University of Technology, Akure, Nigeria.

Baraniak, B., Swieca, M. 2008. Proteolytic modification of selected legume flours. Acta Scientiarum Polonorum Technologia Alimentaria, 7: 41-48.

Burke, D.M. 2002. Liver function: Test selection and 
interpretation of results. Clinical Laboratory Medicine, 22: 377-390.

Duncan, D.B. 1955. Multiple range and multiple F tests. Biometrics, 11: 1-42.

Elegbede, J.A. 1998. Legumes. In: Nutritional Quality of Plant Foods, A.U. Osagie and O.U. Eka, (eds.), pp. 55-83, Post Harvest Research Unit, Department of Biochemistry, University of Benin, Benin city, Nigeria.

MacDonald, J.M. 2008. The Economic Organization of U.S. Broiler Production, Economic Information Bulletin No. 38. Economic Research Service, U.S. Department of Agriculture, Washington, DC., USA.

Malomo, S.O. 2000. Toxicology implication of ceftriaxone administration in rats. Nigerian Journal of Biochemistry and Molecular Biology, 15: 33-38.

Martinez, J.A., Marcross, R., Mararulla, M.T., Larraide, J. 1995. Growth harmonal status and protein turn over in rats fed on a diet containing peas (Pisum sativum L.) as the source of protein. Plant Foods for Human Nutrition, 47: 211-220.

May, J.D., Lott, B.D., Simmons, J.D. 1998. The effect of environmental temperature and body weight on growth rate and feed: gain of male broilers. Poultry Science, 77: 499-501.
Minari, J.B., Odutuga, A.A., Bamisaye, F.A., Dairo, J.O., Fagbohunka, B.S. 2012. Effect of some processing techniques on the proximate and antinutrients composition of Leucaena leucociphala seed. Pakistan Journal of Nutrition, 11: 310-312.

Nakaue, H.S., Arscott, G.H. 1991. Feeding poultry. In: Livestock Feeds and Feeding, D.C. Church, (ed.), $3^{\text {rd }}$ edition, Prentice Hall, International, Inc., Englewood Cliffs, New Jersey, USA.

Oloyede, O.B., Odutuga, A.A., Minari, J.B., Ambali, A.A. 2007. Assessment of some serum metabolites and enzymes of broiler-chickens fed raw and processed Bambara groundnut. International Journal of Poultry Science, 6: 647-650.

Reitman, S., Frankel, S. 1957. A colorimetric method for the determination of serum glutamic oxalacetic and glutamic pyrovic transaminases. American Journal of Clinical Pathology, 28: 56-63.

SAS, 1985. SAS User's Guide: Statistics, Version 5 Edition, SAS Institute, Cary, NC, USA.

Sethi, P., Kulkarni, R. 1995. Leucaena leucocephala: a nutrition profile. Food and Nutrition Bulletin, 16: $224-237$.

Wiryawan, K.G. 1997. Grain Legumes for Poultry. Ph.D. Thesis, The University of Queensland, Australia. 